\title{
Para Onde Estamos Caminhando? Uma Análise das Pesquisas em Governança Corporativa
}

\author{
Where are We Heading? An Analysis of the Corporate Governance Literature
}

Universidade Federal de Santa Catarina, Departamento de Ciências Contábeis, Florianópolis, SC, Brasil ${ }^{1}$

Artigo recebido em 28.11.2017. Última versão recebida em 20.09.2018. Aprovado em 20.09.2018. 


\title{
Resumo
}

A Governança Corporativa tornou-se um dos temas mais discutidos no mundo dos negócios com grande impacto acadêmico e prático. A pesquisa objetiva identificar, a partir da análise da literatura, o desenvolvimento da temática e as oportunidades de pesquisa. A partir da análise de 31 artigos teóricos e 59 artigos empíricos identificaram-se oportunidades de pesquisa dentro de uma abordagem interpretativista e crítica com vistas a orientar estudos em distintos contextos e particularidades. Também foi observada a predominância da Teoria da Agência, todavia com limitada investigação dos conflitos entre acionistas, e entre credores e gestão. As oportunidades de pesquisas voltam-se à compreensão de fenômenos pela análise interligada da Teoria da Agência, Teoria dos Stakeholders, Stewardship e Dependência de Recursos. Foi possível evidenciar, por meio da literatura, que a análise dos mecanismos internos e externos de maneira complementar fornece maiores subsídios às investigações. A pesquisa contribuiu para geração de conhecimento, ao apresentar de maneira sistematizada as principais características dos pesquisadores de GC, os aspectos conceituais e teóricos da área, além de apresentar às potencialidades para futuras pesquisas, quanto à abordagem, teoria e mecanismos de governança corporativa.

Palavras-chave: governança corporativa; revisão de literatura; oportunidades de pesquisa.

\begin{abstract}
Corporate Governance has become one of the most discussed issues in the business world and has had a broad academic and practical impact. By analyzing the literature related to this area, we seek to examine the development of this subject and potential opportunities for research. Based on 31 theoretical and 59 empirical articles, we have been able to identify research opportunities through an interpretative and critical approach designed to guide studies within a variety of contexts and with various characteristics. We have noted a predominance in the use of Agency Theory, but a limited analysis of conflicts among shareholders and between creditors and management. The research opportunities that we have identified focus on the integrated analysis of Agency Theory, Stakeholder Theory, Stewardship Theory and Resource Dependence Theory. It has also been possible to demonstrate through the literature that the analysis of internal and external mechanisms in a complementary manner can make greater contributions to these investigations. This study contributes to the understanding of this area by providing a systematic presentation of the main characteristics of CG researchers, concepts and theoretical aspects, and it also identifies potential areas for future research related to the approach, theory and mechanisms of Corporate Governance.
\end{abstract}

Keywords: corporate governance; literature review; research opportunities.

JEL code: G34, L25, D21. 


\section{Introdução}

A Governança Corporativa (GC) tornou-se um dos temas mais discutidos no mundo dos negócios (Aguilera \& Cuervo-Cazurra, 2004; Bebchuk \& Weisbach, 2010; Denis, 2001; Denis \& McConnell, 2003). Conforme Filatotchev e Boyd (2009), Claessens e Yurtoglu (2013) há aproximadamente uma década (talvez duas) a GC recebia pouca atenção, mesmo na área acadêmica, mas, em pouco tempo, tornou-se objeto de discussão nas organizações, nos eventos acadêmicos, bem como nas políticas de regulação.

A instigação da discussão de GC é, em grande parte, atribuída ao advento das crises financeiras e escândalos corporativos dos anos 2000 (Enron e WorldCom), por questionar principalmente as práticas e a evidenciação efetuada pelas empresas (Aguilera, Desender, Bednar \& Lee, 2015; Chhaochharia \& Laeven, 2009). Porém as intensas atividades de aquisições e restruturação da década de 80 (Christopher, 2010), a inserção dos mecanismos de proteção às aquisições hostis (Holmstrom \& Kaplan, 2001), os elevados níveis de remuneração dos executivos e as crises financeiras da Ásia, Rússia e Brasil na década de 90 (Christopher 2010; Claessens \& Yurtoglu, 2013), também impulsionaram o desenvolvimento da temática.

De maneira abrangente, Aguilera e Cuervo-Cazurra (2004) sinalizam a internacionalização das economias, o desenvolvimento tecnológico, a integração do mercado de capitais e o processo de transformação da estrutura de propriedade das empresas, como fatores relacionados ao crescimento no interesse da GC. Nesse sentido, Claessens e Yurtoglu (2013) adicionam ainda a influência dos intermediários financeiros, da competitividade e dos riscos de mercado.

Vale destacar os impactos da recente crise financeira ao evidenciar as fraquezas da governança que, por consequência, afetaram a confiabilidade dos investidores. Para Aguilera e Cuervo-Cazurra (2004) e Claessens e Yurtoglu (2013) a popularização da GC tanto no âmbito acadêmico, quanto organizacional e político, evidencia a importância e necessidade de sistemas de incentivos e de aprimorar a efetividade dos mecanismos de monitoramento.

Em resposta, diversos países aderiram a regras mais rígidas no que tange ao controle de propriedade, comitês, auditoria independente e responsabilização da gestão no intuito de restabelecer a confiabilidade das informações publicadas. Para tanto, torna-se necessário reconsiderar os modelos e mecanismos relacionados à minimização dos problemas oriundos da assimetria de informação (AlBaidhani, 2014; Christopher, 2010; Filatotchev \& Boyd, 2009; L'Huillier, 2014).

Fatores estes que ocasionaram um crescimento considerável nas pesquisas empíricas de GC em diversas áreas, no intuito de investigar diferentes estruturas de governança e seus impactos (Bebchuk, \& Weisbach, 2010; Durisin \& Puzone, 2009; Larcker, Richardson, \& Tuna, 2007). Por outro lado, uma série de pesquisas empíricas apresentaram resultados inconclusivos ao se fundamentar em uma única abordagem (Aguilera, Filatotchev, Gospel, \& Jackson, 2008; Daily, Dalton, \& Cannella, 2003; Filatotchev, Jackson, \& Nakajima, 2013).

Por conseguinte, surgiram diversas discussões acerca do direcionamento das pesquisas futuras para uma visão mais holística da GC. Essa perspectiva surge a partir da análise das práticas organizacionais, pautando-se não somente em abordagens universalistas como a Teoria da Agência, mas pautado em abordagens organizacionais que melhor podem compreender e auxiliar no desenvolvimento da área (Aguilera, et al., 2008; Filatotchev et al., 2013).

Devido a essa disseminação das pesquisas de GC, e de sua evolução no decorrer dos anos, torna-se pertinente o conhecimento estruturado dos estudos publicados até o momento. Assim, diante dessa percepção surge o seguinte questionamento: Quais as oportunidades de pesquisas na temática de GC, a partir de uma análise da literatura de natureza teórica e empírica? Nesse sentido, a pesquisa tem por objetivo identificar, a partir da análise da literatura, o desenvolvimento da temática de GC e as oportunidades de pesquisa remanescentes. Para tal, fez-se uso de uma ferramenta que conduz a seleção 
de um portfólio de artigos, tanto teóricos quanto empíricos, sobre os quais se possa compreender a evolução da temática.

A pesquisa se justifica pela importância, acadêmica e prática, bem como pelo crescimento do interesse nessa temática por diversas áreas, como economia, finanças, gestão e estratégia (Bebchuk, \& Weisbach, 2010; Larcker et al., 2007). Apesar de a temática emergir pelo destaque atribuído aos escândalos financeiros, trata-se de um tema de grande importância para as organizações atualmente (Christopher, 2010). Larcker, Richardson e Tuna (2007) acrescentam que é difícil imaginar uma situação na qual a GC não seja relevante para a compreensão do comportamento gerencial e desempenho organizacional, considerando a sua contribuição para finalidades estratégicas e operacionais nas organizações.

Outras pesquisas já apresentaram uma compilação dos achados sobre GC, como as de Denis (2001), Daily, Dalton e Cannella (2003), Aguilera, Filatotchev, Gospel e Jackson (2008) e Ahrens, Filatotchev e Thomsen (2011) que criticam a visão closed system e discutem a evolução dos mecanismos de governança corporativa. O levantamento publicado por L'Huillier (2014) aborda os problemas relacionados à ausência de uma filiação teórica e conceitual e assim como Aguilera et al. (2008) e Filatotchev e Boyd (2009) busca introduzir uma abordagem open-system advinda da sociologia que assume as interdependências e incertezas do ambiente organizacional, bem como o seu impacto nas diferentes práticas de GC (Aguilera et al., 2008; Durisin \& Puzone, 2009). No entanto, grande parte da literatura empírica compreende a GC em termos de Teoria de Agência e explora isso em diferentes práticas e em seus consequentes impactos no desempenho (Aguilera et al., 2008).

Contudo, esta pesquisa se diferencia das demais por realizar uma análise sistematizada e por identificar os avanços ocorridos na área, bem como o direcionamento das futuras pesquisas, na medida em que amplia o horizonte temporal. Além disso, a pesquisa propõe-se a apresentar as distintas características e avanços dos artigos teóricos e dos artigos empíricos, pela necessidade de criticar e sintetizar a literatura existente.

Justifica-se a pesquisa, à medida que análises, críticas e sínteses de forma sistematizada se fazem necessárias para a evolução da literatura e para que novos frameworks e perspectivas sobre o tema sejam suscitados. Ademais, a literatura de GC tem sido criticada por apresentar conceitos divergentes que acabam se refletindo em resultados empíricos mistos, dificultando a construção do conhecimento. Verifica-se que, mesmo em décadas de pesquisa sobre a GC, discutir diferentes abordagens faz-se indispensável, de modo que há uma necessidade de mapear e compreende a evolução e as possíveis oportunidades de estudo. Nesse sentido, que o artigo fornece uma análise inteirada das dimensões teóricas que sustentam as pesquisas de governança, bem como dos aspectos recorrentemente empregados nas pesquisas empíricas.

Ademais, esta pesquisa busca contribuir a partir da identificação dos avanços metodológicos, pois críticas dos estudos empíricos pautam-se na observância das práticas de GC de maneira isolada (Ahrens, Filatotchev, \& Thomsen, 2011; Denis, 2001; Filatotchev \& Boyd, 2009; Filatotchev et al., 2013), sendo que o desempenho da organização não pode restringir-se a efetividade de um mecanismo, mas da combinação de mecanismos, vinculados a fatores institucionais (Al-Baidhani, 2014). Além disso, Brickley e Zimmerman (2010) apresentam uma crítica aos índices de GC desenvolvidos nas pesquisas, devido à atribuição de pesos e aos problemas de endogeneidade. Nesse sentido, busca-se contribuir a partir de uma revisão sistematizada, apresentando críticas e oportunidades metodológicas e teóricas para as futuras pesquisas.

\section{Governança Corporativa}

Os possíveis problemas associados à separação de propriedade e controle inerente as corporações modernas pode ser considerado o principal evento a emergir na área da GC (Denis, 2001). 
Nesse sentido, a autora salienta que a maioria dos estudos se pauta na perspectiva introduzida por Adam Smith em 1776, ao abordar a profissionalização da gestão, e retomada em 1932 por Berle e Means ao questionar a sobrevivência da organização. No entanto, o principal marco para a área foi o estudo de Jensen e Meckling (1976) ao aplicar a Teoria da Agência para as organizações modernas e formalizando o modelo de custos de agência do capital externo (Denis, 2001). Hart (1995) reforça que a governança surge em situações de problemas de agência e quando os custos de agência devido a tais problemas não podem ser abrangidos num contrato.

A partir de então, pesquisadores, principalmente sob um viés financeiro, investem esforços para compreender, mensurar e minimizar tais conflitos de interesse, bem como averiguar seu reflexo no valor da firma (Daily et al. 2003; Denis, 2001). Sob esse viés, os autores definem a GC como um conjunto de mecanismos institucionais e de mercado que induzem a gestão para comportamentos cujos interesses próprios de maximizar valor sobrepõem os interesses da organização (Daily et al. 2003; Denis, 2001; Schmidt \& Tyrell, 1997). No entanto, não se tem um consenso acerca da definição de GC (Brickley \& Zimmerman, 2010). Yang, Chi e Young (2011) atribuem essa discordância principalmente à multidisciplinariedade da temática. Apesar da Teoria da Agência predominar nas pesquisas de GC, tem-se um vasto campo de abordagens teóricas a serem explorados, em geral, como complemento à perspectiva da agência (Daily et al., 2003).

Nesta direção que Brickley e Zimmerman (2010) enfatizam a importância de apresentar a afiliação conceitual, devido sua influência no direcionamento da pesquisa, na sua estruturação, bem como subsequente análise. Sendo que elementos como separação de propriedade e controle (Brickley \& Zimmerman, 2010; Claessens \& Yuroglu, 2013; Daily et al., 2003; Denis, 2001; Larcker et al., 2007; Short, Keasey, Wright, Hull, \& Nakajima, 1999) e problema de agência (Agrawal \& Knoeber, 1996; Beiner, Drobetz, Schmid, \& Zimmermann, 2006; Brickley \& Zimmerman, 2010; Filatotchev \& Allcock, 2010, Hart, 1995; Ho, 2005; Mayer, 1998), são inerentes quando a definição tem o viés da Teoria da Agência, baseada em accountability para o acionista, no intuito de melhorar o desempenho.

À medida que características como direitos e responsabilidades, estrutura da corporação e envolvimento de outros stakeholders (Aguilera \& Jackson, 2010; Al-Baidhani, 2014; Beasley, 1996; Brickley \& Zimmerman, 2010; Christopher, 2011; Davis, 2005; Filatotchev \& Allcock, 2010; Filatotchev \& Boyd, 2009; Gillan, 2006; Hart, 1995; Ho, 2005; Huse, 2005; Larcker et al., 2007; L'Huillier, 2014), são provenientes de outras perspectivas teóricas. Da mesma forma, ao se analisar GC como função de interação entre stakeholders e função stewardship (Agrawal \& Knoeber, 1996; Aguilera, et al., 2015; Aguilera \& Jackson, 2010; Ahrens et al., 2011; Al-Baidhani, 2014; Beasley, 1996; Beiner, et al., 2006; Brickley \& Zimmerman, 2010; Claessens \& Yurtoglu, 2013; Daily et al., 2003; Davis, 2005; Denis, 2001; Ho, 2005; Filatotchev \& Allcock, 2010; Filatotchev \& Boyd, 2009; Filatotchev \& Nakajima, 2010; Gaur, Bathula, \& Singh, 2015; L'Huillier, 2014; Mayer, 1998; Tsipouri \& Xanthakis, 2004; Turnbull, 1997;).

Ao analisar a GC enquanto um processo, verifica-se os modelos e mecanismos que assegurem a eficácia na tomada de decisões, no desenvolvimento de práticas de monitoramento, porém também se tem uma preocupação com a eficiência na alocação de recursos, que é uma vertente advinda da Teoria de Dependência de Recursos (Aguilera, et al. 2008; Aguilera \& Jackson, 2010; Brickley \& Zimmerman, 2010; Christopher, 2011; Claessens \& Yurtoglu, 2013; Davis, 2005; Filatotchev \& Allcock, 2010; Filatotchev \& Boyd, 2009; Filatotchev et al., 2013; Gaur et al., 2015; Ho, 2005; L'Huillier, 2014; Short, et al., 1999).

\section{Procedimentos Metodológicos}

Para a geração de conhecimento e identificação das lacunas de pesquisa, efetuou-se a seleção do fragmento da literatura de GC mediante um instrumento estruturado de intervenção, denominado ProKnow-C (Knowledge Development Process - Construtivist). Instrumento proposto e validado nas 
pesquisas de Lacerda, Ensslin e Ensslin (2014), Ensslin, Mussi, Chaves e Demetrio (2015), Ensslin, Ensslin, Dutra, Nunes e Reis (2017) em temáticas de avaliação de desempenho. Como estratégia de validação da operacionalização da pesquisa, efetuou-se o registro de todas as etapas bem como a sinalização de suas delimitações. Posteriormente, os dados foram avaliados e validados por um member checking expert no instrumento, conforme indicado por Creswell e Clark (2013).

\section{Procedimentos para a seleção do portfólio bibliográfico}

A primeira etapa de operacionalização do ProKnow- $C$ consiste na seleção de um Portfólio Bibliográfico (PB) que represente os artigos considerados relevantes para o tema de interesse. Essa etapa consiste em: (a) selecionar um banco de artigos, (b) aplicar procedimentos de filtragem nos artigos, e (c) testar a representatividade dos artigos. A seleção do PB inicia com a definição das palavras-chave e seleção das bases de dados. A partir de então, se procede à busca de artigos nas bases de dados selecionadas de acordo com as palavras-chave definidas e a posterior realização dos testes de aderência das palavras-chave definidas.

Ressalta-se que foram selecionados artigos de natureza teórica (revisões de literatura, propostas de modelos teóricos e críticos-reflexivos) e de natureza empírica (do tipo experimental, levantamento documental, propostas de modelos empíricos). Visto isso, definiram-se dois eixos de pesquisa. O Eixo Principal compreendem as palavras-chave corporate control, corporate governance, governance e governance practice enquanto que o eixo secundário foi segregado em Eixo Teórico e Eixo Empírico. A partir da definiçãao das palavras chave, selecionaram-se as bases de dados, EBSCO, Emerald Group Publishing, ISI Web of Knowledge, ProQuest, Science Direct, Scopus e Wiley Online Library para busca da literatura internacional, e a biblioteca eletrônica Scientific Periodical Electronic Library (SPELL®) para busca nacional. A busca dos artigos teóricos nas bases de dados ocorreu de 26 de setembro a 6 de outubro de 2016, enquanto que a busca dos artigos empíricos foi realizada entre 14 e 19 de dezembro de 2016. Como parâmetro de busca estabeleceu-se a (a) pesquisa nos comandos no título, resumo e palavras-chave das bases de dados; (b) sem limitação de idioma; (c) sem limitação temporal; (d) sem delimitação de área de atuação; e (e) somente artigos publicados em journals.

Dessa forma, foram selecionados 37.341 artigos teóricos e 41.881 artigos empíricos para incorporar o PB. Observa-se que os números iniciais de artigos brutos, foi significativamente alto devido às palavras-chave abrangerem governança em um contexto geral e por abranger diversas áreas de conhecimento. Posteriormente fez-se o teste de aderência das palavras-chave para sua validação e assim efetuar o processo de filtragem e exclusão dos artigos duplicados, que foi operacionalizado pelo software de gerenciamento bibliográfico EndNote ${ }^{\circledR} X 7$. Esse processo de exclusão de duplicados resultou em um PB de 27.790 artigos teóricos e 32.267 artigos empíricos, dos quais se realizou a leitura dos títulos para verificar o alinhamento com o tema.

Após a leitura dos títulos, o Portfólio Teórico passou a ser composto por 222 artigos e o Portfólio Empírico composto por 681 artigos. A partir destes estudos, efetuou-se a análise de representatividade pelo do volume de citações pelo Google Scholar e a leitura dos resumos. Nessa etapa, selecionaram-se os artigos com mais de 30 citações dos quais se efetuou a leitura dos resumos, resultando em 42 artigos teóricos e 58 artigos empíricos alinhados. Além disso, analisaram-se os artigos cujo reconhecimento científico ainda não foi confirmado (por possuírem menos de 30 citações), porém que foram publicados recentemente (2014 a 2016), incorporando-se mais 5 artigos teóricos e 17 artigos empíricos.

Na sequência, procedeu-se à leitura integral dos artigos, no intuito de verificar o alinhamento com a temática, permanecendo 29 artigos teóricos e 52 artigos empíricos. Posteriormente, efetuou-se o teste de representatividade pela análise das referências, incorporando-se mais dois artigos ao PB teórico, totalizando 31 artigos. Ao PB empírico foram incorporados 7 artigos, totalizando 59 artigos, que representam o fragmento da literatura na área de GC com base na percepção dos pesquisadores. A etapa de seleção dos PBs é destacada na Figura 1. 


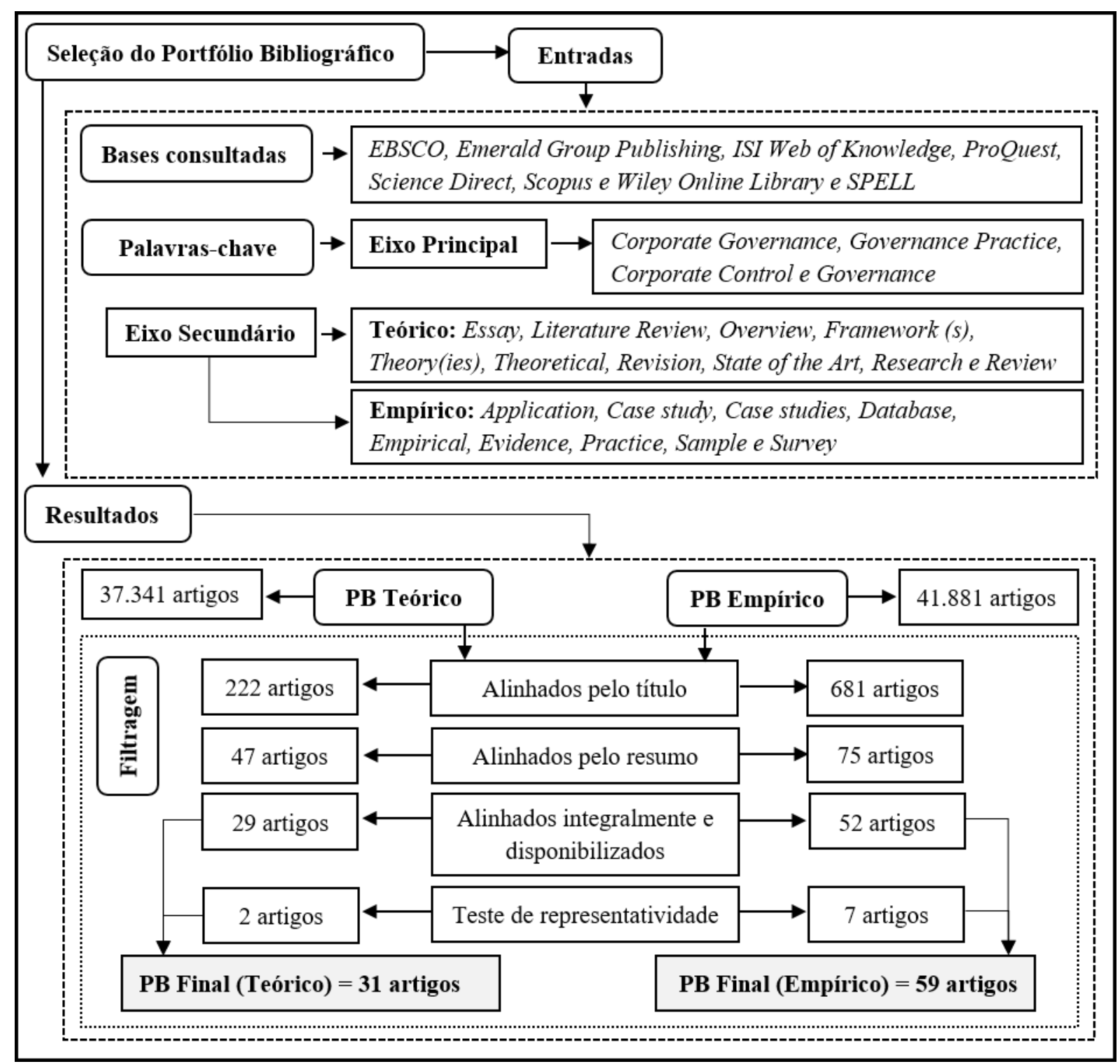

Figura 1. Processo de Seleção dos Artigos

Fonte: Dados da pesquisa.

A etapa que consiste na realização da análise bibliométrica dos artigos, busca identificar as características das publicações, a partir da contagem de ocorrência dos pesquisadores com trajetória na área, periódicos (além do cruzamento com as referências), reconhecimento científico dos artigos, evolução temporal dos estudos e colaboração dos autores/coautores. Em uma análise adicional, efetuou-se a classificação dos artigos nos paradigmas de pesquisa (positivista/funcionalista, interpretativista ou crítico), com base nas definições de Burrell e Morgan (1979), Goles e Hirschheim (2000) e Lukka (2010), que representam a visão de mundo dos pesquisadores.

A partir de então, por meio de uma análise crítica dos artigos selecionados, dispõe-se a fornecer subsídios de contribuição à literatura, observaram-se os elementos da GC (em termos de características, funções e processo), afiliação teórica adotada nos artigos, a evolução dos enfoques temáticos e as oportunidades de pesquisa. 


\section{Resultados}

Definido o PB que representa um fragmento da literatura de GC composto por 31 artigos teóricos e 59 artigos empíricos efetuou-se a avaliação crítica. Inicialmente efetuou-se a análise de características (pesquisadores com trajetória na área, periódicos, cooperação dos autores/coautores, paradigmas de pesquisa), e posterior análise conceitual da afiliação teórica e das oportunidades de pesquisa.

\section{Caracterizações das pesquisas}

Observa-se que nos 31 artigos teóricos, predomina o desenvolvimento de artigos de maneira

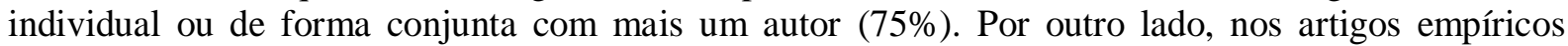
verificou-se a predominância do desenvolvimento em grupos de três ou mais autores (60\% dos artigos). Vale destacar que o desenvolvimento de artigos empíricos com até dois autores prevalece nos artigos mais antigos. Essa característica dos artigos empíricos observa-se pelas redes de colaboração existentes entre autores de universidades diferentes, seja no mesmo país (40\% dos artigos), ou pela colaboração entre autores de universidades de países diferentes (29\% dos artigos).

Ademais, verificou-se nos estudos empíricos a colaboração dos autores com representantes de empresas ou órgãos federais, como ocorreu nos artigos de Kim e Limpaphayom (1998), Klapper e Love (2004), Bebchuk e Cohen (2005), Thomsen, Pedersen e Kvist (2006), Adams e Ferreira (2009), Bebchuk, Cohen e Ferrell (2009), Chhaochharia e Laeven (2009). A motivação para a existência de redes de colaboração consiste na acessibilidade de dados e aplicação de estudos em ambientes e países com amostras diferenciadas. Além disso, vale sinalizar a área de pesquisa e formação dos autores, por exemplo, num artigo tem-se um estatístico e um autor com conhecimento na área de GC. Na sequência, efetuou-se a análise dos autores de destaque de ambos os portfólios (Figura 2), no intuito de verificar a existência dos autores mais profícuos de GC.

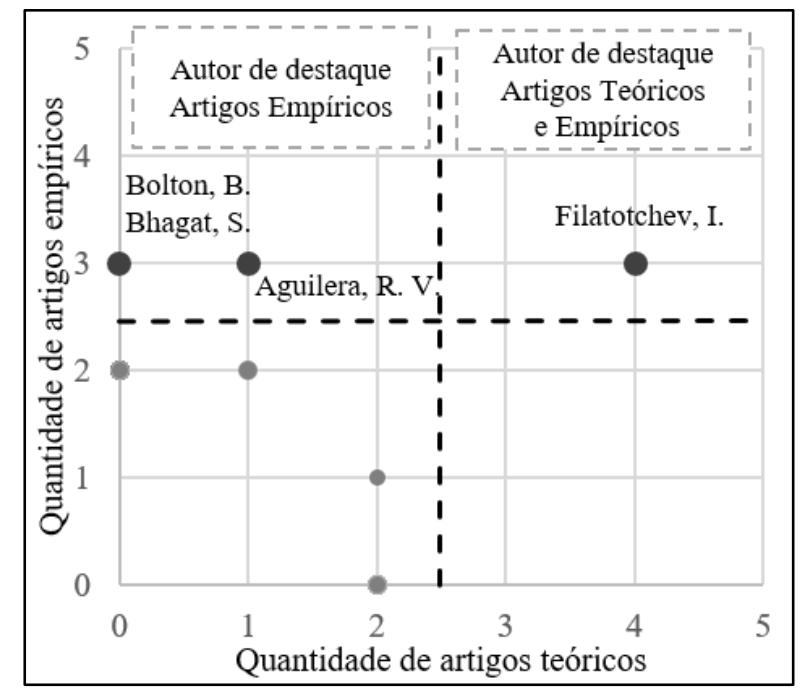

Figura 2. Autores de Destaque

Fonte: Elaborada pelos autores.

De maneira geral, observa-se que os autores publicam artigos apenas de natureza teórica ou empírica, identificando-se somente Igor Filatotchev da City University London como autor de destaque em ambos os portfólios. Pela análise dos 59 artigos empíricos, identifica-se uma disseminação entre os autores, com destaque para Ruth Aguilera, Sanjai Bhagat e Brian Bolton.

Salienta-se que dos quatro artigos teóricos de Filatotchev, três possuem uma abordagem interpretativista, alertando sobre a necessidade de outras abordagens para além da Teoria da Agência 
na GC. Além de despertar sobre a interface dos mecanismos internos e externos, e por questionar a eficácia da GC a partir do advento das crises financeiras. Em estudo desenvolvido em 2010 com Nakajima, evidenciam dois eixos de discussões na GC, um primeiro dominado pela economia e finanças, explorando os conflitos de interesse; e um segundo eixo que abrange as teorias organizacionais. $\mathrm{O}$ autor, mesmo explorando a área sob um viés empírico, sempre ressalta a importância de uma abordagem integrativa, buscando complementar a Teoria da Agência mediante inserção de outras teorias.

Posterior à identificação dos autores com trajetória estabelecida sobre GC, realizou-se o cruzamento com os autores de destaque das referências. Essa análise permite inferir e confirmar a importância de Sanjai Bhagat (University of Colorado), Bernard Black (diretor da SSRN) e Brian Bolton (Portland State Univesity), para o âmbito empírico da GC. Black em seus estudos voltou-se para a análise das práticas de governança de empresas de países emergentes, por meio de índices. Enquanto que Bhagat e Bolton (2008) buscavam comparar índices de GC para predizer o desempenho corporativo, com a inserção de novos elementos.

Destaca-se também Ruth Aguilera que transita entre a área teórica e empírica. Teoricamente aborda os conceitos de governança em diferentes perspectivas, da mesma forma, busca adotar empiricamente a abordagem open systems. Além de relatar a importância do ambiente legal, auditoria, ativismo e analistas como mecanismos para prevenir a maximização da riqueza dos agentes, ressaltando ainda a importância de integrar mecanismos internos e externos. Em um estudo desenvolvido com Cuervo-Cazurra, analisaram os códigos de governança de diferentes países, no intuito de observar a influência de características específicas dos países.

Analisados os autores, foram levantados os periódicos que publicam artigos nessa temática (Figura 3), identificando-se uma multidisciplinariedade nos periódicos que publicaram artigos teóricos, envolvendo outras áreas, como sociologia, direito e administração.

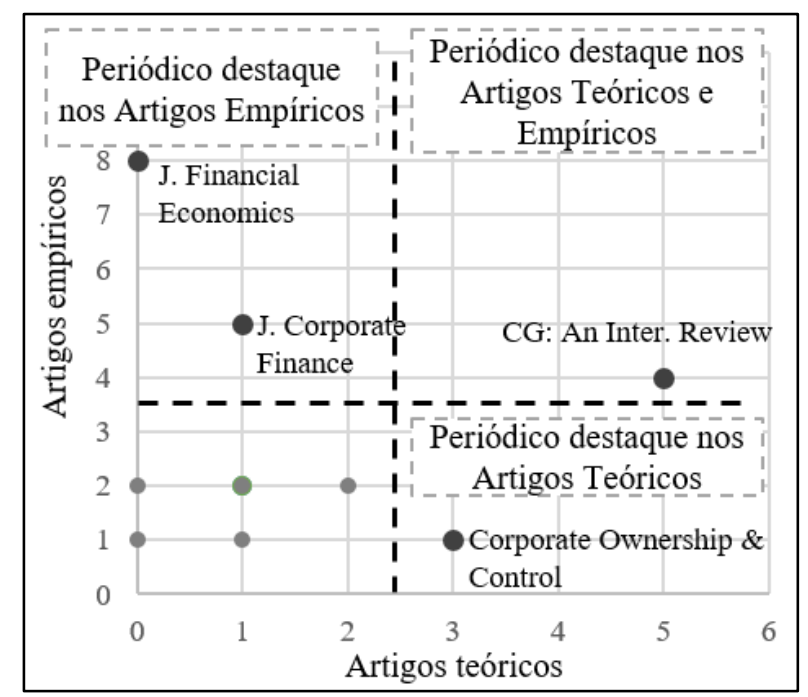

Figura 3. Periódicos de Destaque

Fonte: Elaborada pelos autores.

Por outro lado, na análise dos artigos empíricos, tem-se a predominância dos periódicos com escopo na área de finanças e economia, com um viés positivista. No intuito de identificar um journal que tenha uma aceitabilidade tanto de pesquisas teóricas e empíricas, destaca-se o Corporate Governance: An International Review, do Reino Unido, onde Kumar e Zattoni são os atuais editores. No entanto, nos artigos empíricos vale destacar a relevância dos periódicos Journal of Financial Economics (8 artigos) e Journal of Corporate Finance (5 artigos).

Na sequência, identificaram-se os paradigmas de pesquisa, que demostram como os autores observam e interpretam a temática, podendo ser classificado como positivista, interpretativista ou

RAC, Rio de Janeiro, v. 23, n. 1, art. 3, pp. 43-66, janeiro/fevereiro, 2019, http://rac.anpad.org.br (cc) Er 
crítico, a partir da conceituação de Burrell e Morgan (1979) e Lukka (2010). A análise dos paradigmas demonstra que a maioria dos pesquisadores observa a GC a partir de um olhar determinista, mediante uma abordagem voltada ao problema, pautada na identificação e medição de relações empíricas. Identifica-se a necessidade dos autores em apontar relações de causa e efeito, e buscar explicações com base na objetividade, apenas para a situação analisada, pautado no status quo.

Nas pesquisas empíricas, verifica-se a exploração e aplicação de estudos em diferentes contextos, países ou setores, no intuito de confirmar ou refutar o comportamento de um determinado fenômeno em diferentes óticas. O mesmo se estende para os estudos que propõem modificações nos índices de GC e buscam testar sua aplicabilidade e poder explicativo em diferentes contextos. Essa predominância de pesquisas positivistas, já assinalada por Lukka (2010) na área gerencial, recebe críticas de pesquisadores teóricos por serem visões geralmente baseadas em uma única Teoria (da Agência), a qual restringe as organizações a dois atores principais (principal e agente).

Ao analisar os artigos teóricos, também se verifica a predominância do viés positivista (55\%), caracterizada pela exposição da literatura, limitando-se a análise de autores, citações e áreas de pesquisa, baseando-se na descrição de estudos. Enquanto que outros estudos se limitam à exposição dos mecanismos (principalmente ao conselho de administração), pautando-se somente na abordagem econômica da Teoria da Agência (Claessens \& Fan, 2002; Huse, 2005). No entanto, ressaltam a necessidade de incorporar outras abordagens para a compreensão dos fenômenos (Daily et al., 2003; Filatotchev \& Boyd, 2009; L'Huillier, 2014).

Vale destacar a mudança de cenário mediante inserção da visão interpretativista às pesquisas, principalmente devido às crises financeiras que colocaram em pauta a eficácia da GC e ressaltaram suas limitações. Aguilera, Florackis e Kim (2016) atribuem o crescimento no interesse da temática ao papel da GC na alocação de recursos, de modo a afetar estratégias, criação e distribuição de valor.

Dessa forma, sinaliza-se a oportunidade de desenvolver pesquisas com abordagem interpretativista e crítica. Assim como a utilização de vertentes teóricas diferentes da Teoria da Agência, como será explorado mais a frente, ou explorar a Teoria da Agência a partir da perspectiva de conflitos de interesses entre principais, ou credor e principal, que poucos explorados nos estudos. Nesse sentido, Aguilera et al. (2016) orientam acerca dos problemas com endogeneidade nas estimações empíricas e sugerem a combinação de pesquisas em banco de dados, com aplicação de questionários e entrevistas, para a compreensão dos fenômenos.

\section{Análise dos conceitos e teorias}

Com a finalidade de explorar os conceitos de GC apresentados nos artigos, realizou-se um levantamento dos elementos (características, funções e processos) mais frequentes nas pesquisas teóricas e empíricas. Para tanto, levantaram-se nos 90 artigos os conceitos dados de forma direta (pelos autores dos trabalhos) e de forma indireta (diante de citação) para GC e, posteriormente, efetuou-se a classificação.

Pela análise dos artigos teóricos, verifica-se uma diversidade de definições advindas de outras áreas como sociologia, direito, economia, enquanto que pela análise dos artigos empíricos, os conceitos são mais restritos à área de negócios. Nos artigos empíricos observa-se uma recorrente ausência de conceitos (70\%), enquanto que nos artigos teóricos, somente $23 \%$ dos artigos não apresentaram definições. Essa característica foi apresentada por Marie L'Huillier (2014) ao identificar que, aproximadamente, 9 a cada 10 artigos não apresentam uma definição de GC (principalmente nas empíricas). Vale ressaltar que, do total, somente 18 artigos apresentaram conceituações próprias.

Além disso, verificou-se que os conceitos apresentados nos artigos empíricos são, em sua maioria, citações de outros autores, principalmente de Shleifer e Vishny (1997) pela perspectiva de agência. Diante disso, é possível afirmar que os estudos (principalmente empíricos) partem de um entendimento pré-determinado pela comunidade científica sobre GC, sendo perceptível de maneira 
geral uma afiliação à Teoria da Agência, corroborando com Aguilera et al. (2008). No entanto, vale ressaltar que dependendo da filiação teórica a compreensão da GC é diferente.

Pela análise dos artigos que declararam um conceito, identificaram-se conceitos de diferentes áreas, influenciados pelas afiliações profissionais, contextos institucionais e culturais e pela visão de mundo dos pesquisadores (Gillan, 2006; Turnbull, 1997). Além de ser influenciado pelo objeto ou contexto legal estudado. Observa-se que algumas definições são mais abrangentes, ao fazer referência a fatores contextuais aplicados a diversas instituições. A observação dessas características vai ao encontro de Aguilera e Jackson (2010). Na sequência, apresentam-se as características da GC identificadas nos estudos teóricos e empíricos (Figura 4).

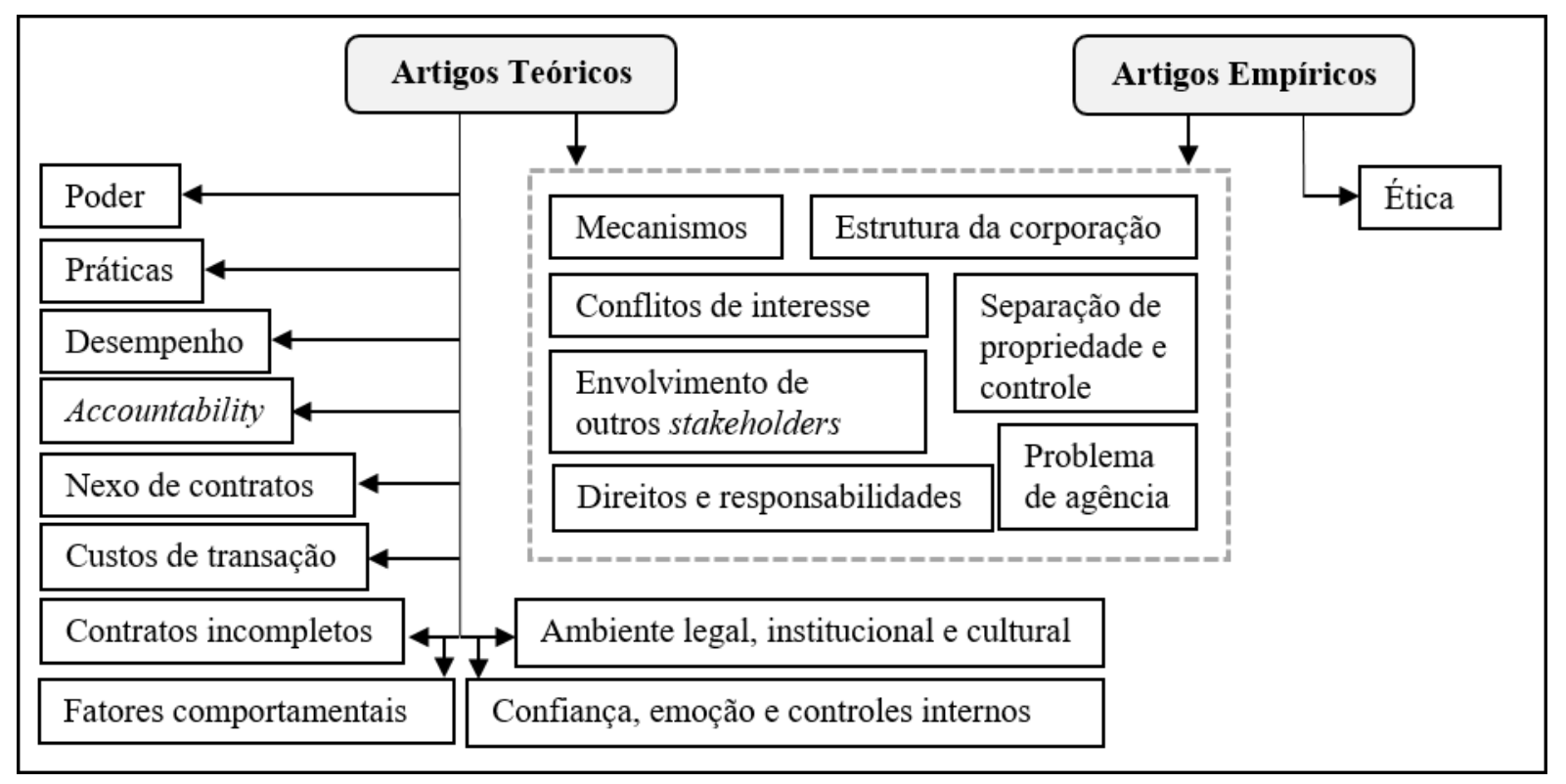

Figura 4. Características da GC

Fonte: Elaborada pelos autores.

Em relação às características Hart (1995) afirma como necessária numa definição de GC, a existência de conflito de agência e nexo de contratos (custos de transação). A primeira condição, referente aos conflitos de interesse envolvendo membros da organização, apresenta-se tanto nos artigos teóricos quanto empíricos, sendo o principal aspecto abordado pela Teoria da Agência. Além disso, nessa perspectiva, assume-se a relação entre diferentes práticas de governança e desempenho das empresas, sendo o papel da governança assegurar que a empresa opere de acordo com os interesses dos acionistas (Ahrens et al., 2011; Filatotchev \& Boyd, 2009).

Por outro lado, os custos de transação, oriundos de contratos incompletos, são abordados somente nos artigos teóricos (Hart, 1995), sendo a governança um mecanismo para direcionar o comportamento do agente ao cumprimento dos objetivos e interesses do principal, bem como nortear as decisões não especificadas no contrato inicial. No entanto, Claessens e Yurtoglu (2013) salientam que nem todos os pesquisadores concordam com a visão da GC sob o aspecto de acordos contratuais. Uma segunda perspectiva é pautada no enquadramento normativo, baseada nas regras de funcionamento das empresas, que são provenientes do sistema legal, jurídico, do mercado financeiro.

Dentre as outras características, aspectos comuns nos artigos teóricos e empíricos são os mecanismos, direitos e responsabilidade e integração com os demais stakeholders (Christopher, 2010, 2011; Daily et al., 2003; Huse, 2005; Turnbull, 1997). A visão de direitos e responsabilidades dos envolvidos é oriunda da Teoria dos Stakeholders. Essa perspectiva implica em mecanismos que assegurem que os gestores respeitam os interesses e direitos dos stakeholders da empresa, da mesma forma que garantam que os stakeholders atuem com responsabilidade em relação à proteção, geração e distribuição da riqueza investida na empresa (Aguilera \& Jackson, 2003; Al-Baidhani, 2014). 
O elemento accountability, para minimizar os riscos do acionista, assegurar seus benefícios e auxiliar a gestão, de modo que se tenha um beneficio com o crescimento da empresa, é uma perspectiva pouco explorada empiricamente (Ahrens et al., 2011; Filatotchev \& Boyd, 2009). Por outro lado, nos artigos teóricos, Aguilera e Jackson (2010), alertam para as diferenças de governança conforme a diversidade das dinâmicas das empresas e países. A perspectiva sociológica critica a visão funcionalista quanto à conceituação, apresentando uma interpretação alternativa baseada no poder, cultura, network e confiança, além do comportamento do conselho de administração (Davis, 2005; Huse, 2005). Além disso, L'Huillier (2014) salienta que pela perspectiva da Teoria de Dependência de Recursos, observa-se a estrutura da organização em relação ao ambiente no qual se encontra a organização.

Os estudos empíricos e teóricos também abordam a influência do conselho de administração e suas interações com os demais stakeholders. Porém, Brickley e Zimmerman (2010) criticam o foco somente no conselho de administração, uma vez que existem outros mecanismos que exercem influência e podem impactar na empresa. Porém, ressalta-se que somente nos artigos empíricos prevaleceu a característica de ética no conceito de governança, sendo que para obter padrões de boa governança, faz-se necessária qualidade ética, além da relação com funcionários, clientes, fornecedores, a fim de prevenir comportamentos impróprios (Ho, 2005). Na Figura 5, apresentam-se as funções da GC identificadas a partir da análise das definições de ambos os portfólios.

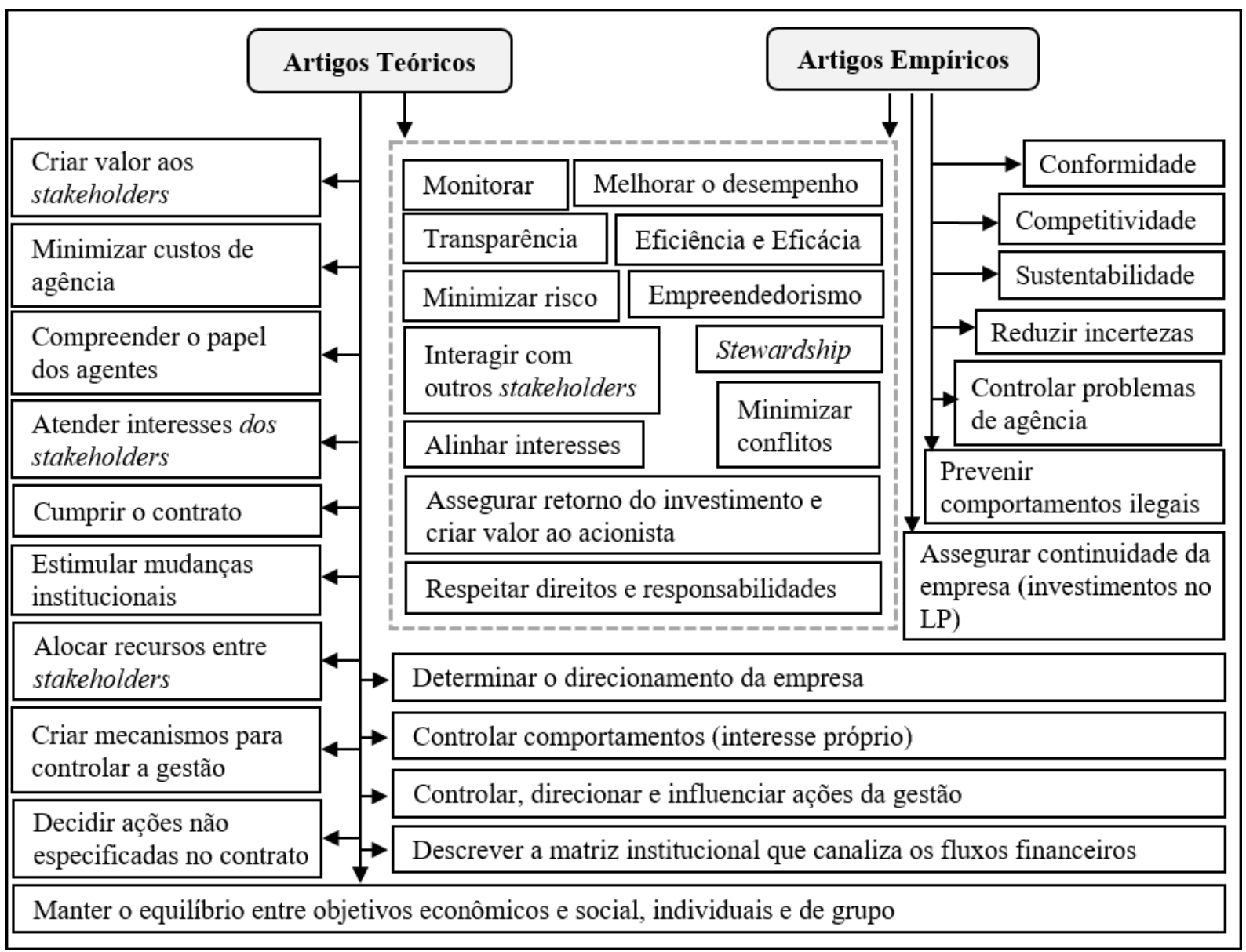

Figura 5. Funções da GC

Fonte: Elaborada pelos autores.

Da mesma forma como foram levantadas as características identificaram-se as funções conforme as definições de GC. Assim sendo, tanto os artigos teóricos como empíricos possuem como preocupação principal, o acionista, por meio da criação de valor, garantia de retorno, minimização do risco, melhora no desempenho e otimização de recursos, tendo por base o artigo de Shleifer e Vishny (1997).

RAC, Rio de Janeiro, v. 23, n. 1, art. 3, pp. 43-66, janeiro/fevereiro, 2019, http://rac.anpad.org.br $((c))$ 
Além disso, identifica-se a função de stewards exercida pelos gestores, buscando sempre o melhor resultado para a empresa e não o interesse financeiro próprio (Ho, 2005; L'Huillier, 2014; Short et al., 1999). Em relação aos stakeholders, idenfica-se uma preocupação com a maximização de sua riqueza, alocação de recursos e alcance de seus interesses (Aguilera \& Jackson, 2010; Claessens \& Yurtoglu, 2013; Davis, 2005; Huse, 2005; Filatotchev \& Boyd, 2009; L'Huillier, 2014; Turnbull, 1997).

Quanto às outras funções realça-se a criação de mecanismos, o controle e monitoramento das ações e decisões da gestão, no intuito de evitar que busquem por benefícios próprios. Outro aspecto observado é o direcionamento futuro da empresa, por meio da relação entre diversos participantes, observado nos artigos teóricos. Os artigos empíricos até abordam o longo prazo, pela competitividade, sustentabilidade, continuidade da empresa, buscando administrar com eficiência e eficácia, porém não em seu objetivo final. A partir da análise da GC como um processo, identificaram-se os elementos apresentados na Figura 6.

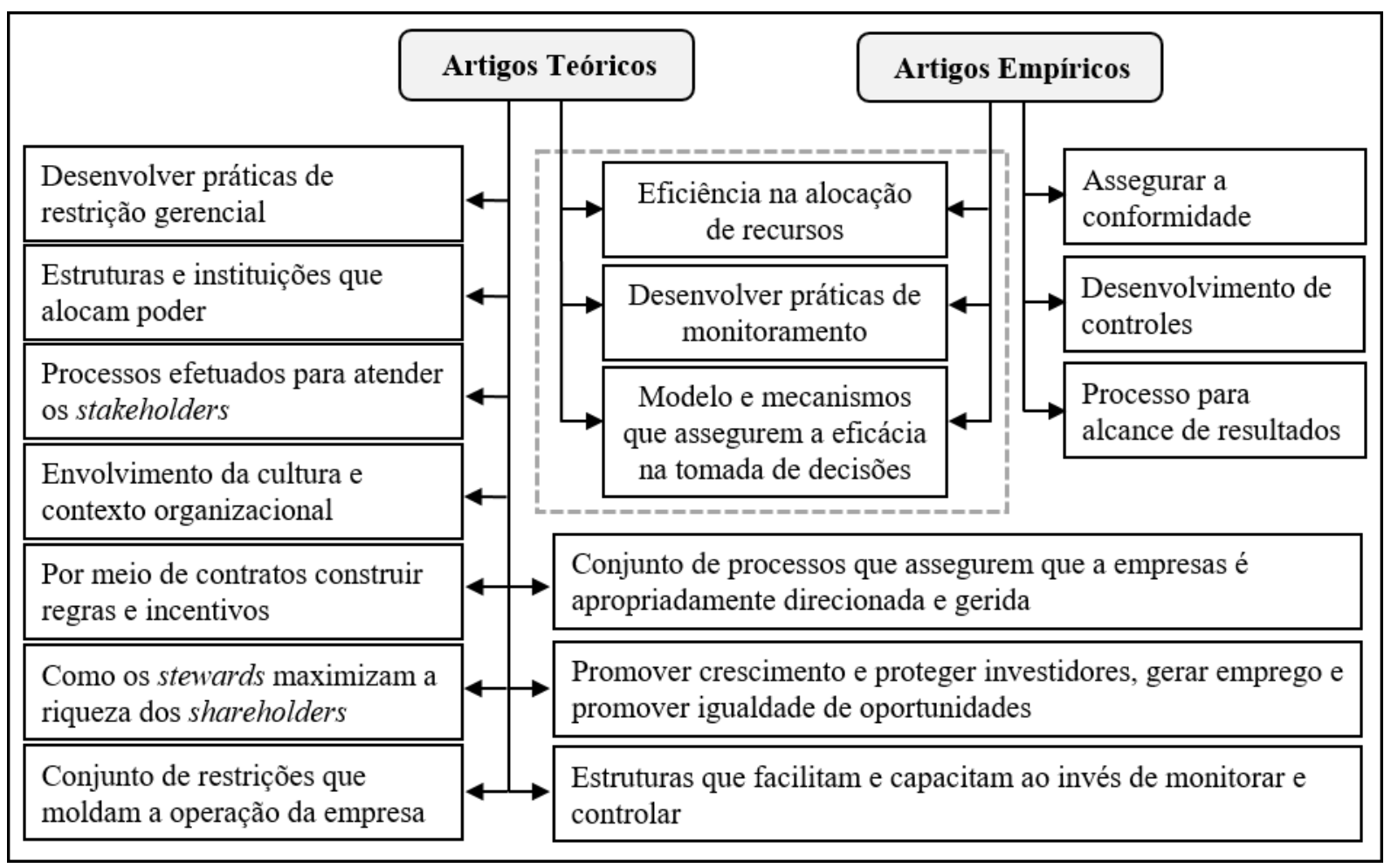

Figura 6. Processos Associados ao Conceito de GC

Fonte: Elaborada pelos autores.

Em relação aos processos destacados nos estudos empíricos, verificou-se uma grande preocupação com a conformidade e alcance de resultados, sendo possível pelo desenvolvimento de novos controles internos ou pelo seu aprimoramento. Nesse sentido, Christopher (2011) salienta a forma que os objetivos da empresa são delimitados, monitorados e avaliados, de modo que o desempenho seja otimizado. Além disso, o autor justifica a governança como uma forma de assegurar que as organizações sejam direcionadas e gerenciadas apropriadamente.

Nos artigos teóricos, identificou-se como o processo mais recorrente, o conjunto de restrições que moldam a operação da empresa, bem como a tomada de decisão. Filatotchev, Jackson e Nakajima (2013), Brickley e Zimmerman (2010) e L'Huillier (2014) conceituam a GC como um conjunto de práticas organizacionais cujo objetivo é monitorar e restringir a discricionariedade gerencial, considerando a governança como uma forma de controlar os agentes, sob a ótica da Teoria da Agência. 
Além dessa preocupação com a adequada gestão e monitoramento dos agentes, e de todas as influências, sejam de poder, de cultura, de regras, surge à preocupação de como os agentes (enquanto stewards) maximizam a riqueza dos acionistas, mas também em como a organização pode atender os demais stakeholders. Aguilera e Jackson (2010) e L'Huillier (2014) abordam a governança como um veículo para garantir os interesses dos stakeholders, sendo uma forma de reduzir a assimetria e assegurar os direitos de todos os envolvidos.

A perspectiva da alocação de recursos se insere na GC como estruturas, processos e instituições (dentro e fora) da organização que alocam poder e controlam recursos (Davis, 2005). Insere-se assim a abordagem de eficiência e eficácia na administração dos recursos, por meio de uma abordagem política, não somente para a sobrevivência das empresas, mas também para manter o comprometimento. Conforme Filatotchev e Boyd (2009) a governança é responsável pelo desempenho da empresa, por exemplo, a alocação de recursos deve ser efetuada de forma produtiva para satisfazer todos os stakeholders, da mesma forma quando os recursos precisam ser reduzidos, a governança é responsável por uma adequada redução de custos.

Dessa forma, reforça-se a importância de se apresentar a filiação conceitual nas pesquisas, pois o conceito norteará o direcionamento da pesquisa, impactará na sua estrutura, bem como na metodologia a ser utilizada (Brickley \& Zimmerman, 2010; L'Huillier, 2014). Pela análise das definições, as evidências mostram, em sua maioria, uma afiliação a perspectiva de agência, no intuito de compreender o papel dos agentes na relação contratual, assim como do monitoramento das ações do agente. Nesse sentido, a perspectiva da agência esta associada à GC por meio dos mecanismos de controle das ações do agente, para maximizar a riqueza do acionista e não do agente.

Porém, verificou-se também a inserção de outras perspectivas teóricas, como por exemplo, Teoria de Dependência de Recursos, advinda da sociologia (Aguilera et al., 2015; Christopher, 2010, 2011; Daily et al., 2003; Gugler, Mueller, \& Yurtoglu, 2008; L'Huillier, 2014; Turnbull, 1997; Yoshikawa, Zhu, \& Wang, 2014). Essa Teoria é voltada para a estrutura da organização e sua relação com o ambiente externo, sendo a influência de expertise do conselho de administração, um dos aspectos mais explorados. Destaca-se também a Teoria Stewardship, que considera que o gestor busca trabalhar no intuito de alcançar o melhor resultado para a empresa e seus shareholders, e não para alcançar de benefícios de interesse próprio (Christopher, 2010, 2011; Daily et al., 2003; L'Huillier, 2014; Turnbull, 1997). Por fim, tem-se a Teoria dos Stakeholders, cuja visão não é pautada somente no benefício do acionista (como na Teoria da Agência), mas também nos funcionários, credores, fornecedores, entre outros grupos de interesse (Aguilera \& Jackson, 2010; Christopher, 2010, 2011; Daily et al., 2003; Huse, 2005; L’Huillier, 2014; Turnbull, 1997).

Diante dessa análise, reforça-se o apontado por Turnbull (1997), L'Huillier (2014) e Aguilera, Desender, Bednar e Lee (2015) que cada definição está associada com a visão do pesquisador, por exemplo, estudiosos com viés da área econômica e de finanças partem da definição de Shleifer e Vishny (1997), relacionado ao retorno do investimento. Por outro lado, a visão sociológica está relacionada à alocação de poder e de recursos (Davis, 2005) e a perspectiva stakeholders associada aos direitos e responsabilidades de todos os interessados da organização (Aguilera et al., 2008).

Conforme Ahrens et al. (2011) a Teoria da Agência vem sendo tratada como uma teoria universal que se aplica a diferentes contextos institucionais. Diante dessa perspectiva, atribui-se à governança o papel de minimizar os conflitos de interesses entre agente e principal e maximizar valor ao acionista (Denis, 2001; Denis \& Mcconnell, 2003; Hart, 1995; Mayer, 1998; Shleifer \& Vishny, 1997). Isso se reflete em sua popularidade nas pesquisas da área, sendo a teoria mais utilizada.

Observam-se diversas críticas à Teoria da Agência, principalmente por reduzir as corporações a dois participantes (gestores e acionistas) cujos interesses assumidos por ambos são claros. Nesse sentido, Daily et al. (2003) salientam que, até o momento, os pesquisadores preocupavam-se somente com a proteção dos interesses dos acionistas, voltando-se para a análise da eficácia dos diversos mecanismos para salvaguardar esses interesses. 
Identificou-se que até 2003, a Teoria da Agência era a perspectiva mais recorrente tanto nas pesquisas empíricas, quanto teóricas. Porém, a partir deste momento outras perspectivas teóricas foram introduzidas, enquanto que nos artigos empíricos essa inserção denotou maior tempo. Em 2003, Daily et al. introduziram a visão de que a empresa possui outros grupos de interesse para além do acionista. Sendo que em 2005, Huse, reforçou que a GC é muito mais ampla que o monitoramento do agente. A partir deste momento, inseriu-se uma perspectiva voltada à influência de outras áreas e teorias que contribuem com a GC, além de se ampliar o foco que até então era dado somente ao acionista para a inserção de outros stakeholders, bem como a inserção de outros aspectos como mercado, cultura e regulação (Gillan, 2006).

A partir de 2005, verifica-se um crescimento nas vertentes teóricas utilizadas na governança, principalmente das teorias organizacionais. Porém, destaca-se que outras perspectivas teóricas não buscaram explicar e compreender fenômenos de maneira isolada, mas sim de maneira integrada, complementando outras teorias e, principalmente a Teoria da Agência. Emergiu então a discussão em torno da importância de uma abordagem multiteórica para o entendimento da GC. Daily et al. (2003) reforçam essa abordagem por ser essencial para o reconhecimento dos diversos mecanismos e estruturas que podem melhorar o funcionamento das organizações. Porém, essas relações ainda estão em desenvolvimento, não encontrando-se formalizadas ainda, mas são de extrema importância para os avanços à área.

Desataca-se que a utilização de abordagens alternativas à Teoria da Agência, não surgiram no intuito de a substituírem, mas sim de complementar e suprir as deficiências e críticas a ela atribuídas. Destaca-se a pesquisa de Christopher (2010) que apresenta um modelo teórico no qual integra a visão da Teoria da Agência, dos Stakeholders, Stewardship e Dependência de Recursos para uma melhor compreensão da GC e seus impactos nas diferentes organizações. Sendo que pesquisas recentes, como L'Huillier (2014) também integram o conceito de governança para essas teorias.

Em relação aos artigos empíricos, identifica-se a GC inserida no contexto de problemas de agência e conflitos de interesse, como nas pesquisas de Brickley, Coles e Terry (1994), Agrawal e Knoeber (1996), Tsipouri e Xanthakis (2004). Sendo que, recentemente, (principalmente a partir de 2010), verifica-se uma mudança nas pesquisas empíricas, abordando diferentes aspectos da Teoria da Agência, como, por exemplo, o conflito entre principais, e valorização de outros stakeholders das organizações (Aguilera et al., 2015; Chung, Elder, \& Kim, 2010).

\section{Oportunidades de pesquisa}

Num primeiro momento apresentam-se as oportunidades de pesquisa identificadas no que tange aos mecanismos de governança empregados, sejam internos ou externos. Pela análise dos mecanismos internos identificaram-se como oportunidades de pesquisa a influência da ética e dos códigos de conduta tanto nas organizações, quanto nos indivíduos, e o papel da reputação como mecanismo. Outros aspectos, pouco explorados, são as influências das características de dívida e uso de stock options como incentivos. Além disso, é importante analisar a relação dos diversos comitês com controles internos, criação de valor e accountability. Os artigos sugerem ainda a investigação da influência da participação do governo, funcionários, bancos e instituições sem fins lucrativos na estrutura de propriedade e gestão, a apresentação dos custos e benefícios da propriedade concentrada e a influência da estrutura de propriedade nas políticas de investimento e financiamento.

Conforme o levantamento efetuado, um dos temas mais recorrentes em se tratando de mecanismos internos de GC, é o conselho de administração (Daily et al., 2003; Filatotchev \& Boyd, 2009). No entanto, tem-se um grande número de pesquisas empíricas desenvolvidas nessa temática, e uma carência de pesquisas teóricas. Ahrens et al. (2011) salientam que estudos que analisam somente a estrutura do conselho de administração, tendem a ser rejeitados. Como oportunidades de pesquisas, aponta-se a investigação de fatores como a expertise e efetiva independência do conselho de administração, conexões políticas, gênero no conselho de administração, e seus impactos na gestão da 
empresa, no desempenho, na competitividade e estratégias de negócios, a partir da incorporação de outras abordagens teóricas.

Em relação aos mecanismos externos, identificaram-se como lacunas a relação da auditoria e analistas na criação de valor e accountability, a natureza da proteção legal dos investidores e sua associação com os sistemas de governança e se o ativismo do investidor acrescenta ou destrói valor para a empresa. Outras lacunas encontradas foram em relação ao pagamento de dividendos como mecanismo de governança, a investigação dessas diferenças na influência da regulação, da política e economia, a influência dos grupos de interesse na ineficiência dos sistemas de governança, além de investigar a influência do sistema legal no nível de governança. Um assunto com grande atratividade são as fraudes e sua relação com a governança, principalmente no que se refere a falhas e ineficácia da organização que não são apontadas.

Muitos autores criticam a análise do efeito isolado de mecanismos, argumentando ser necessária a investigação da interface de mecanismos (Ahrens et al., 2011; Denis, 2001; Filatotchev \& Boyd, 2009; Filatotchev et al., 2013), uma vez que o desempenho da empresa não se restringe à efetividade de um único mecanismo (Al-Baidhani, 2014). Verifica-se ainda que as pesquisas são homogêneas, não sendo possível generalizações para diferentes contextos (Aguilera et al., 2008). De forma a ressaltar a importância de pesquisas com abordagens mais amplas, considerando-se interdependências, principalmente para evidenciar a importância prática.

Diante disso, tem-se como oportunidade para futuras pesquisas a investigação das diferenças no grau de importância do conjunto de mecanismos, conforme características de país e setores (financeiro), analisar o comportamento dos mecanismos de governança em períodos de crise e em períodos pós-crise (Daily et al., 2003) e em como equilibrar os mecanismos internos e externos (complementariedade ou substituibilidade). Além disso, sugere-se analisar os efeitos de características de governança interna sobre as escolhas de governança externa (Filatotchev \& Nakajima, 2010). Os autores ainda complementam sobre a importância de analisar o efeito do papel do conselho e do ativismo do investidor na liderança e empoderamento de empregados para a eficácia da GC.

Metodologicamente, Ahrens et al. (2011) destacam a atribuição de maior importância à significância econômica nas pesquisas e não somente a significância estatística. Além disso, Filatotchev e Nakajima (2010), Filatotchev et al. (2013) sugerem que para uma análise comparativa e de aspectos institucionais, faz-se necessária a triangulação das informações, mediante uso de dados de diferentes fontes como, por exemplo, combinar informações estatísticas com questionários, entrevistas e grupos focais para efetuar as inferências, buscando alcançar maior profundidade nas explicações de um determinado fenômeno. Complementarmente, Daily et al. (2003) alertam sobre a necessidade do uso de dados primários no desenvolvimento das pesquisas.

Como observado pela análise conceitual, grande parte da influência da GC ocorre através da Teoria da Agência, que é pautada no conflito de interesses de gestores e acionistas. No entanto, existem outros tipos de conflitos de interesses, que são pouco observados nas investigações teóricas e empíricas. Um exemplo disso é o conflito de interesses entre principais, ou seja, entre acionistas majoritários e acionistas minoritários, que prevalece em empresas cuja propriedade é concentrada, com baixa proteção ao investidor (Chhillar \& Lellapalli, 2015). Outro conflito de interesse pouco explorado nas pesquisas é entre credores e gestão/acionistas, uma vez que os credores fornecem recursos e possuem direitos sobre o fluxo de caixa da empresa, instituindo assim covenants.

Além disso, existe uma grande ênfase e necessidade de discussão dos aspectos teóricos na área. Visto que grande parte das discussões é pautada na Teoria da Agência, ressalta-se a necessidade de integrar essa visão com outras teorias, não somente teoricamente, mas também empiricamente, para que ocorra uma evolução na área. Sendo necessária a análise das interdependências entre a organização e o ambiente que influenciam nas variações da eficácia de diferentes práticas de GC (Filatotchev \& Nakajima, 2010). Nesse sentido, apresenta-se na Figura 7 uma taxionomia da GC a partir de diferentes perspectivas teóricas. 


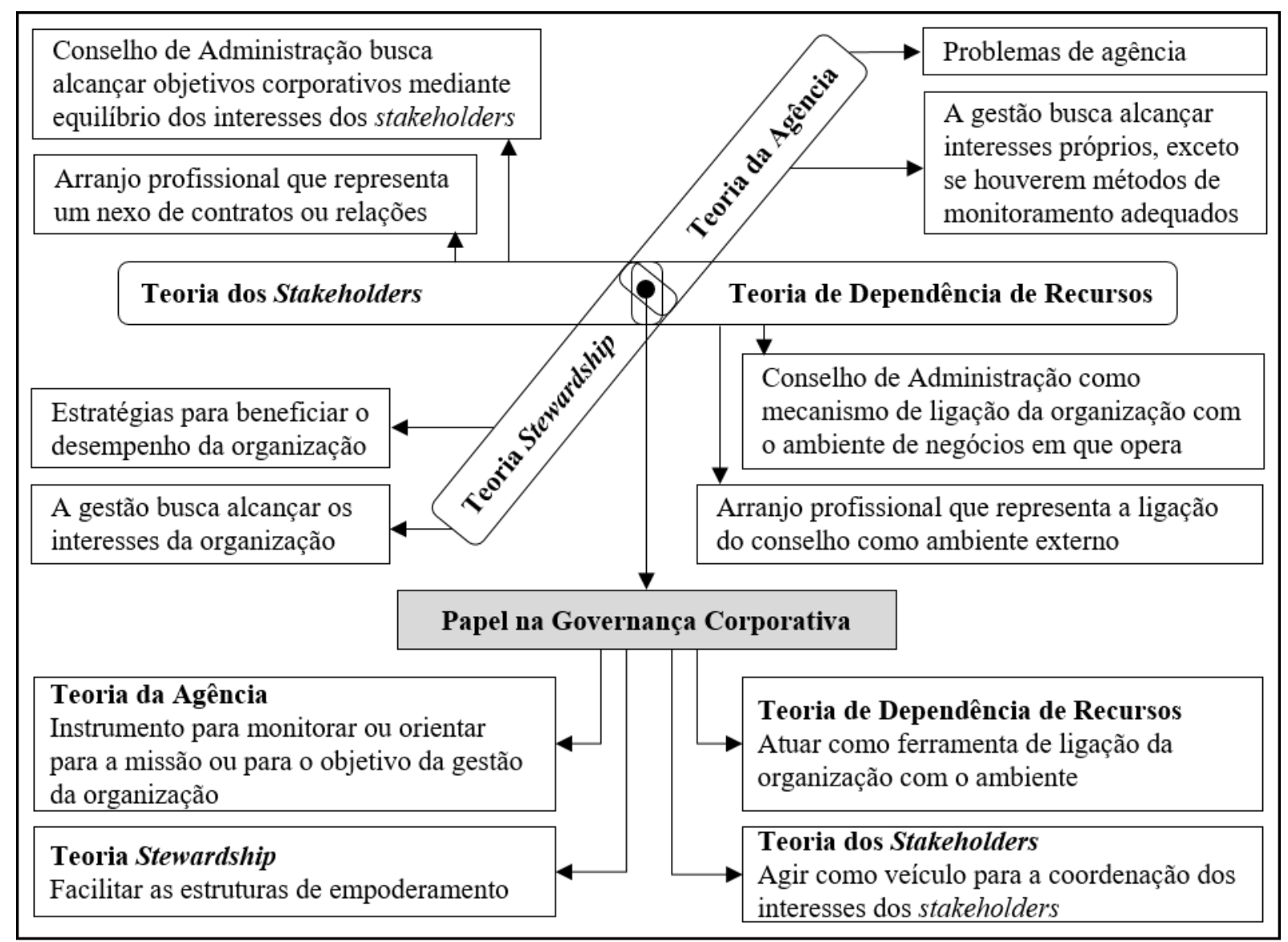

Figura 7. Oportunidades de Pesquisa

Fonte: Elaborada pelos autores a partir da taxionomia de L'Huillier, B. M. (2014). What does "corporate governance" actually mean? (p. 303). Corporate Governance: The International Journal of Business in Society, 14(3), 300-319. https://doi.org/10.1108/CG-10-2012-0073

A partir dessa taxionomia de integração de aspectos de diferentes teorias, vislumbra-se um leque de oportunidades de pesquisa, que contribuem para o avanço teórico da área. Nesse sentido, Aguilera et al. (2008) destacam a importância de abordar nos estudos de governança a perspectiva de open system com abordagens organizacionais, por considerar as características da organização como interdependentes com diversidade, flutuações e incertezas do ambiente.

A Teoria Stewardship busca compreender o papel dos agentes, assumindo que não é influenciado pelo interesse próprio, mas é provável de ser afetado pela situação estrutural em que se encontra, além de maximizar o valor dos shareholders, uma vez que em algumas situações os gestores concluem que atender os interesses dos shareholders, também beneficia a eles próprios (Daily et al., 2003; L'Huillier, 2014). Nesse sentido, L'Huillier (2014) salienta que a aplicabilidade da Teoria Stewardship não se volta à motivação do CEO, mas sim à estrutura de empoderamento para incrementar a eficácia e gerar maior retorno ao shareholder, no lugar de controle e monitoramento. Identifica-se, nesse sentido, uma lacuna voltada para o estudo da influência do steward na maximização da empresa e dos shareholders.

Pela análise da Teoria de Dependência de Recursos, verifica-se sua influência na GC a partir da estrutura e papel do conselho de administração na organização (L'Huillier, 2014). Christopher (2010, 2011) compartilha da mesma perspectiva, salientando que o direcionamento das futuras pesquisas segue para influência da qualidade e efetividades do conselho de administração no acesso de recursos.

A Teoria dos Stakeholders busca o alinhamento de todos os interessados da organização, sendo papel do conselho de administração buscar a convergência de interesses (L'Huillier, 2014). Nesse 
sentido, que se sugere a continuidade das pesquisas, no intuito de buscar respostas a como reduzir o conflito desses interessados.

Além dessas perspectivas de maior destaque, vale também citar a Teoria da Hegemonia Gerencial que aplicada na GC refere-se a um arranjo onde os conselheiros possuem um papel de suporte aos gestores, exercendo um papel superficial, pois quem toma as decisões estratégicas são os gestores (L'Huillier, 2014). Daily et al. (2003) ainda elenca a aplicabilidade da Teoria da Sinalização, em casos de IPO, além de uma perspectiva legal e política para a compreensão do conselho de administração. Filatotchev et al. (2013) que também enfatizam a necessidade de uma visão holística para a governança, sugerem o uso da Teoria Institucional para a compreensão da efetividade da governança em relação a fatores organizacionais, sociais e políticos.

A visão holística busca contribuir para uma melhor compreensão do trade-off da GC, devido ao impacto na estratégia, recursos e desempenho (Filatotchev \& Nakajima, 2010). Sendo assim, a Teoria dos Stakeholders, Stewardship e Dependência de Recursos removem algumas dessas deficiências da Teoria da Agência (Christopher, 2010, 2011). No entanto, ainda não se há uma estrutura formalizada do impacto da GC em diferentes ambientes organizacionais. L'Huillier (2014) salienta que apesar dessa perspectiva ser pouco desenvolvida na área da GC, não devemos desconsiderá-la, pois pode trazer benefícios e auxiliar no entendimento da GC.

\section{Conclusões}

Esta pesquisa teve por objetivo identificar, a partir da análise da literatura, o desenvolvimento da temática de GC e as oportunidades de pesquisa remanescentes. Para consecução da pesquisa, selecionaram-se 31 artigos teóricos e 59 empíricos, dos quais se efetuou a análise de características, paradigmas de pesquisa, análise conceitual e teórica e identificação de oportunidades de pesquisa.

Pela análise das características, identificou-se Igor Filatotchev como pesquisador destaque no âmbito teórico e empírico. Ressalta-se que no âmbito empírico tem-se uma maior disseminação de pesquisadores, enquanto que os artigos teóricos são mais centrados em alguns autores principais. Além disso, o periódico Corporate Governance: An International Review, possui uma grande influência na área, seja empírica seja teórica. Enquanto que outros journals possuem um foco mais restrito a abordagens positivistas.

Quanto à análise dos paradigmas, observou-se uma predominância do paradigma positivista também nas pesquisas teóricas. Porém verifica-se como oportunidade de pesquisas, o crescimento da visão interpretativista na área de GC, principalmente no que se refere à introdução de abordagens teóricas diferenciadas da Teoria da Agência.

Pela análise conceitual verificou-se o destaque a elementos, como a separação de propriedade e controle, os problemas de agência, os mecanismos de monitoramento, os direitos e responsabilidades, aspectos da estrutura da corporação e o envolvimento de outros stakeholders. Em relação às funções, destaca-se o fato de assegurar o retorno do investimento, minimizar conflitos, alinhar interesses, melhorar o desempenho, monitoramento, minimizar o risco, transparência, eficiência e eficácia e função stewardship. GC, enquanto processo, reflete-se em modelos e mecanismos que assegurem a eficácia na tomada de decisões, desenvolvimento de práticas de monitoramento e na eficiência na alocação de recursos.

Nesse sentido, identificou-se uma predominância de aspectos relacionados à Teoria da Agência, pautada na visão de conflitos entre gestão e controle. Porém, salienta-se a baixa utilização de outros tipos de conflitos (entre acionistas, credores e gestão/acionista). Além disso, identificou-se um crescimento nas pesquisas voltadas para a análise de integração entre outras Teorias, como Stakeholders, Stewardship e Dependência de Recursos para a evolução da área de GC. Sendo que, 
nessa perspectiva, concentram-se as principais oportunidades de pesquisa, conforme pode ser visualizado na Figura 8.

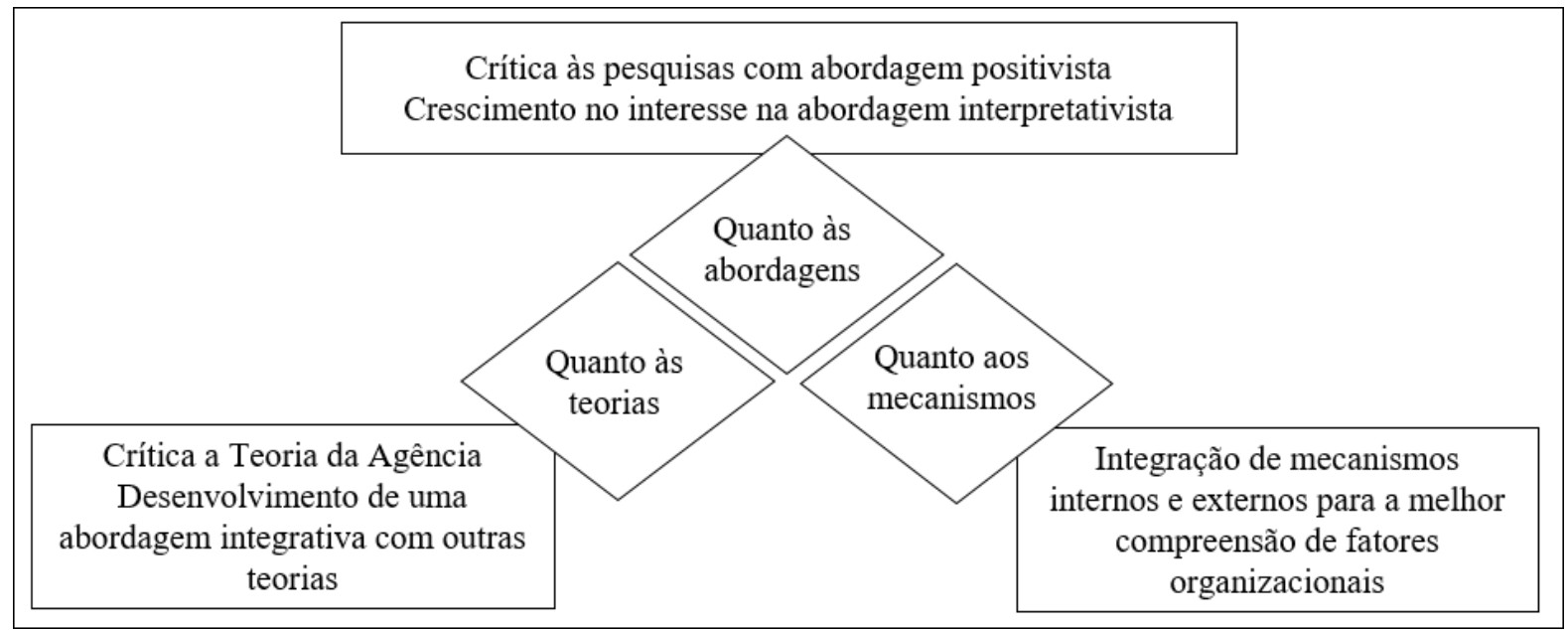

Figura 8. Possibilidades de Pesquisa

Fonte: Elaborada pelos autores.

Como limitações da pesquisa, observa-se a restrição aos artigos escritos em língua inglêsportuguês, publicados em revistas científicas indexadas nas bases selecionadas. Além disso, elenca-se o julgamento dos pesquisadores para seleção e análise dos artigos.

\section{Agradecimentos}

Agradecemos o apoio financeiro recebido da Coordenação de Aperfeiçoamento Pessoal de Nível Superior (CAPES) por meio de bolsa de estudos a primeira autora. Somos gratos as contribuições de Fernanda Maciel Peixoto e José Roberto Ferreira Savoia durante o Seminários em Administração da USP (SemeAd, 2017) e agradecemos os valiosos comentários e contribuições da Professora Sandra Ensslin (Universidade Federal de Santa Catarina) em versões preliminares do artigo. Somos gratos ao editor e aos avaliadores anônimos pelas sugestões para melhorar esta pesquisa.

\section{Material Suplementar}

Todos os dados e materiais foram disponibilizados publicamente por meio da plataforma Mendeley e podem ser acessados em: Kreuzberg, Fernanda; Vicente, Ernesto (2018), "Data for: "Where Are We? An analysis of Corporate Governance Literature" published by RAC-Revista de Administração Contemporânea", Mendeley Data, v1http://dx.doi.org/10.17632/fjn2cb9xnm.1

\section{Contribuições}

$1^{\circ}$ autor: Definição de pesquisa, desenvolvimento teórico e metodológico, redação e revisão final.

$2^{\circ}$ autor: Definição de pesquisa, desenvolvimento teórico, redação e revisão final. 


\section{Referências}

Adams, R. B., \& Ferreira, D. (2009). Women in the boardroom and their impact on governance and performance. Journal of Financial Economics, 94(2), 291-309. https://doi.org/10.1016/j.jfineco.2008.10.007

Agrawal, A., \& Knoeber, C. R. (1996). Firm performance and mechanisms to control agency problems between managers and shareholders. Journal of Financial and Quantitative Analysis, 31(3), 377-397. https://doi.org/10.2307/2331397

Aguilera, R. V., \& Cuervo-Cazurra, A. (2004). Codes of good governance worldwide: What is the trigger? Organization Studies, 25(3), 415-443. https://doi.org/10.1177/0170840604040669

Aguilera, R. V., Desender, K., Bednar, M. K., \& Lee, J. H. (2015). Connecting the dots: Bringing external corporate governance into the corporate governa Nesse sentido, apresenta-se uma taxionomia da GC a partir de nce puzzle. Academy of Management Annals, 9(1), 483-573. https://doi.org/10.1080/19416520.2015.1024503

Aguilera, R.V., Filatotchev, I., Gospel, H., \& Jackson, G. (2008). An organizational approach to comparative corporate governance: Costs, contingencies, and complementarities. Organization science, 19(3), 475-492. https://doi.org/10.1287/orsc.1070.0322

Aguilera, R. V., Florackis, C., \& Kim, H. (2016). Advancing the corporate governance research agenda. Corporate Governance: An International Review, 24(3), 172-180. https://doi.org/10.1111/corg.12167

Aguilera, R. V., \& Jackson, G. (2003). The cross-national diversity of corporate governance: Dimensions and determinants. Academy of management Review, 28(3), 447-465. https://doi.org/10.2307/30040732

Aguilera, R. V., \& Jackson, G. (2010). Comparative and international corporate governance. The Academy of Management Annals, 4(1), 485-556. https://doi.org/10.1080/19416520.2010.495525

Ahrens, T., Filatotchev, I., \& Thomsen, S. (2011). The research frontier in corporate governance. The Journal of Management and Governance, 15(3), 311-325. https://doi.org/10.1007/s10997-0099115-8

Al-Baidhani, A. M. (2014). Review of corporate governance bundle. Corporate Ownership \& Control, 11(4), 236-241. https://doi.org/10.22495/cocv11i4c2p1

Beasley, M. S. (1996). An empirical analysis of the relation between the board of director composition and financial statement fraud. The Accounting Review, 71(4), 443-465.

Bebchuk, L. A., \& Cohen, A. (2005). The costs of entrenched boards. Journal of Financial Economics, 78(2), 409-433. https://doi.org/10.1016/j.jfineco.2004.12.006

Bebchuk, L., Cohen, A., \& Ferrell, A. (2009). What matters in corporate governance? The Review of Financial Studies, 22(2), 783-827. https://doi.org/10.1093/rfs/hhn099

Bebchuk, L. A., \& Weisbach, M. S. (2010). The state of corporate governance research. The Review of Financial Studies, 23(3), 939-961. https://doi.org/10.1093/rfs/hhp121

Beiner, S., Drobetz, W., Schmid, M. M., \& Zimmermann, H. (2006). An integrated framework of corporate governance and firm valuation. European Financial Management, 12(2), 249-283. https://doi.org/10.1111/j.1354-7798.2006.00318.x

Berle, A., \& Means, G. (1932). The modern corporation and private property. New York: MacMillan.

RAC, Rio de Janeiro, v. 23, n. 1, art. 3, pp. 43-66, janeiro/fevereiro, 2019, http://rac.anpad.org.br [(cc)] 
Bhagat, S., \& Bolton, B. (2008). Corporate governance and firm performance. Journal of Corporate Finance, 14(3), 257-273. https://doi.org/10.1016/j.jcorpfin.2008.03.006

Brickley, J. A., Coles, J. L., \& Terry, R. L. (1994). Outside directors and the adoption of poison pills. Journal of Financial Economics, 35(3), 371-390. https://doi.org/10.1016/0304-405X(94)900388

Brickley, J. A., \& Zimmerman, J. (2010). Corporate governance myths: Comments on Armstrong, Guay and Weber. Journal of Accounting and Economics, 50(2/3), 235-245. https://doi.org/10.1016/j.jacceco.2010.10.002

Burrell, G., \& Morgan, G. (1979). Sociological paradigms and organizational analysis: Elements of the sociology of corporate life. London: Heinemann.

Chhaochharia, V., \& Laeven, L. (2009). Corporate governance norms and practices. Journal of Financial Intermediation, 18(3), 405-431. https://doi.org/10.1016/j.jfi.2008.10.001

Chhillar, P., \& Lellapalli, R. V. (2015). Divergence or convergence: paradoxes in corporate governance? Corporate Governance: The International Journal of Business in Society, 15(5), 693-705. https://doi.org/10.1108/CG-05-2015-0066

Christopher, J. (2010). Corporate governance: A multi-theoretical approach to recognizing the wider influencing forces impacting on organizations. Critical Perspectives on Accounting, 21(8), 683695. https://doi.org/10.1016/j.cpa.2010.05.002

Christopher, J. (2011). The multi theoretical approach to governance: Authenticating the concept and establishing its control framework. Corporate Ownership \& Control, 8(3), 18-27. https://doi.org/10.22495/cocv8i3p2

Chung, K. H., Elder, J., \& Kim, J. C. (2010). Corporate governance and liquidity. Journal of Financial and Quantitative Analysis, 45(2), 265-291. https://doi.org/10.1017/S0022109010000104

Claessens, S., \& Fan, J. P. (2002). Corporate governance in Asia: A survey. International Review of Finance, 3(2), 71-103. https://doi.org/10.1111/1468-2443.00034

Claessens, S., \& Yurtoglu, B. B. (2013). Corporate governance in emerging markets: A survey. Emerging Markets Review, 15(1), 1-33. https://doi.org/10.1016/j.ememar.2012.03.002

Creswell, J. W., \& Clark, V. L. P. (2013). Pesquisa métodos mistos. Porto Alegre: Penso.

Daily, C. M., Dalton, D. R., \& Cannella, A. A., Jr. (2003). Corporate governance: Decades of dialogue and data. Academy of Management Review, 28(3), 371-382. https://doi.org/10.2307/30040727

Davis, G. F. (2005). New directions in corporate governance. Annual Review of Sociology, 31, 143162. https://doi.org/10.1146/annurev.soc.31.041304.122249

Denis, D. K. (2001). Twenty-five years of corporate governance research...and counting. Review of Financial Economics, 10(3), 191-212. https://doi.org/10.1016/S1058-3300(01)00037-4

Denis, D. K., \& McConnell, J. J. (2003). International corporate governance. The Journal of Financial and Quantitative Analysis, 38(1), 1-36. https://doi.org/10.2307/4126762

Durisin, B., \& Puzone, F. (2009). Maturation of corporate governance research, 1993-2007: An assessment. Corporate Governance: An International Review, 17(3), 266-291. https://doi.org/10.1111/j.1467-8683.2009.00739.x

Ensslin, L., Mussi, C. C., Chaves, L. C., \& Demetrio, S. N. (2015). It outsourcing management: The state of the art recognition by a constructivist research process and bibliometrics. Journal of 
Information Systems and Technology Management, 12(2), 3-28. http://doi.org/10.4301/S180717752015000200010

Ensslin, L., Ensslin, S. R., Dutra, A., \& Nunes, N. A., \& Reis, C. (2017). BPMgovernance: A literature analysis of performance evaluation. Business Process Management Journal, 23(1), 71-86. https://doi.org/10.1108/BPMJ-11-2015-0159

Filatotchev, I., \& Allcock, D. (2010). Corporate governance and executive remuneration: A contingency framework. The Academy of Management Perspectives, 24(1), 20-33. https://doi.org/10.5465/amp.24.1.20

Filatotchev, I., \& Boyd, B. (2009). Taking stock of corporate governance research while looking to the future. Corporate Governance: An International Review, 17(3), 257-265. https://doi.org/10.1111/j.1467-8683.2009.00748.x

Filatotchev, I., Jackson, G., \& Nakajima, C. (2013). Corporate governance and national institutions: A review and emerging research agenda. Asia Pacific Journal of Management, 30(4), 965-986. https://doi.org/10.1007/s10490-012-9293-9

Filatotchev, I., \& Nakajima, C. (2010). Internal and external corporate governance: An interface between an organization and its environment. British Journal of Management, 21(3), 591-606. https://doi.org/10.1111/j.1467-8551.2010.00712.x

Gaur, S. S., Bathula, H., \& Singh, D. (2015). Ownership concentration, board characteristics and firm performance: A contingency framework. Management Decision, 53(5), 911-931. https://doi.org/10.1108/MD-08-2014-0519

Gillan, S. L. (2006). Recent developments in corporate governance: An overview. Journal of Corporate Finance, 12(3), 381-402. https://doi.org/10.1016/j.jcorpfin.2005.11.002

Goles, T., \& Hirschheim, R. (2000). The paradigm is dead, the paradigm is dead... long live the paradigm: the legacy of Burrell and Morgan. Omega, 28(3), 249-268. https://doi.org/10.1016/S0305-0483(99)00042-0

Gugler, K., Mueller, D. C., \& Yurtoglu, B. B. (2008). Insider ownership, ownership concentration and investment performance: An international comparison. Journal of Corporate Finance, 14(5), 688-705. https://doi.org/10.1016/j.jcorpfin.2008.09.007

Hart, O. (1995). Corporate governance: Some theory and implications. The Economic Journal, 105(430), 678-689. https://doi.org/10.2307/2235027

Ho, C.-K. (2005). Corporate governance and corporate competitiveness: An international analysis. Corporate Governance: An International Review, 13(2), 211-253. https://doi.org/10.1111/j.1467-8683.2005.00419.x

Holmstrom, B., \& Kaplan, S. N. (2001). Corporate governance and merger activity in the US: Making sense of the 1980s and 1990s. The Journal of Economic Perspectives, 15(2), 121-144. https://doi.org/10.1257/jep.15.2.121

Huse, M. (2005). Corporate governance: Understanding important contingences. Corporate Ownership \& Control, 2(4), 41-50. https://doi.org/10.22495/cocv2i4p3

Jensen, M., \& Meckling, W. (1976). Theory of the firm: Managerial behavior, agency costs and ownership structure. Journal of Financial Economics, 3(4), 305-360. https://doi.org/10.1016/0304-405X(76)90026-X 
Kim, K. A., \& Limpaphayom, P. (1998). A test of the two-tier corporate governance structure: The case of Japanese keiretsu. Journal of Financial Research, 21(1), 37-51. https://doi.org/10.1111/j.1475-6803.1998.tb00268.x

Klapper, L. F., \& Love, I. (2004). Corporate governance, investor protection, and performance in emerging markets. Journal of Corporate Finance, 10(5), 703-728. https://doi.org/10.1016/S0929-1199(03)00046-4

Lacerda, R. T. D. O., Ensslin, L., \& Ensslin, S. R. (2014). Research opportunities in strategic management field: A performance measurement approach. International Journal of Business Performance Management, 15(2), 158-174. https://doi.org/10.1504/IJBPM.2014.060165

Larcker, D. F., Richardson, S. A., \& Tuna, I. (2007). Corporate governance, accounting outcomes, and organizational performance. The Accounting Review, 82(4), 963-1008 https://doi.org/10.2308/accr.2007.82.4.963

L'Huillier, B. M. (2014). What does "corporate governance" actually mean? Corporate Governance: The International Journal of Business in Society, 14(3), 300-319. https://doi.org/10.1108/CG10-2012-0073

Lukka, K. (2010). The roles and effects of paradigms in accounting research. Management Accounting Research, 21(2), 110-115. https://doi.org/10.1016/j.mar.2010.02.002

Mayer, C. (1998). Financial systems and corporate governance: A review of the international evidence. Journal of Institutional and Theoretical Economics, 154(1), 144-165.

Schmidt, R. H., \& Tyrell, M. (1997). Financial systems, corporate finance and corporate governance. European Financial Management, 3(3), 333-361. https://doi.org/10.1111/1468-036X.00047

Shleifer, A., \& Vishny, R. W. (1997). A survey of corporate governance. The Journal of Finance, 52(2), 737-783. https://doi.org/10.1111/j.1540-6261.1997.tb04820.x

Short, H., Keasey, K., Wright, M., Hull, A., \& Nakajima, C. (1999). Corporate governance: From accountability to enterprise. Accounting and Business Research, 29(4), 337-352. https://doi.org/10.1080/00014788.1999.9729592

Thomsen, S., Pedersen, T., \& Kvist, H. K. (2006). Blockholder ownership: Effects on firm value in market and control based governance systems. Journal of Corporate Finance, 12(2), 246-269. https://doi.org/10.1016/j.jcorpfin.2005.03.001

Tsipouri, L., \& Xanthakis, M. (2004). Can corporate governance be rated? Ideas based on the Greek experience. Corporate Governance: An International Review, 12(1), 16-28. https://doi.org/10.1111/j.1467-8683.2004.00340.x

Turnbull, S. (1997). Corporate governance: Its scope, concerns and theories. Corporate Governance: An International Review, 5(4), 180-205. https://doi.org/10.1111/1467-8683.00061

Yang, J., Chi, J., \& Young, M. (2011). A review of corporate governance in China. Asian-Pacific Economic Literature, 25(1), 15-28. https://doi.org/10.1111/j.1467-8411.2011.01283.x

Yoshikawa, T., Zhu, H., \& Wang, P. (2014). National governance system, corporate ownership, and roles of outside directors: A corporate governance bundle perspective. Corporate Governance: An International Review, 22(3), 252-265. https://doi.org/10.1111/corg.12050 


\section{Autores}

\section{Fernanda Kreuzberg}

Campus Reitor João David Ferreira Lima, s/n, Trindade, 88040-900, Florianópolis, SC, Brasil.

E-mail: fernandakreuzberg@gmail.com

\section{Ernesto Fernando Rodrigues Vicente}

Campus Reitor João David Ferreira Lima, s/n, Trindade, 88040-900, Florianópolis, SC, Brasil.

E-mail: ernesto.vicente@ufsc.br 